\title{
A Review of Transcranial Magnetic Stimulation in the in vivo Functional Evaluation of Central Cholinergic Circuits in Dementia
}

\author{
Raffaele Nardone $^{a, c}$ Stefan Golaszewski ${ }^{a, b}$ Gunther Ladurner ${ }^{b}$ \\ Frediano Tezzon ${ }^{c}$ Eugen Trinka ${ }^{a}$ \\ a Department of Neurology, Christian Doppler Clinic, Paracelsus Medical University, and beuroscience Institute, \\ Christian Doppler Clinic, Salzburg, Austria; ' Department of Neurology, Franz Tappeiner Hospital, Merano, Italy
}

\section{Key Words}

Transcranial magnetic stimulation $\cdot$ Short-latency afferent inhibition · Cholinergic circuits · Alzheimer disease ·

Dementia with Lewy bodies $\cdot$ Frontotemporal dementia •

Vascular dementia

\begin{abstract}
Central cholinergic circuits of human brain can be tested non-invasively by coupling electrical peripheral stimulation with transcranial magnetic stimulation (TMS) of the motor cortex. The short-latency afferent inhibition (SAl) is reduced in cholinergic forms of dementia, such as Alzheimer disease (AD) and dementia with Lewy bodies, while it is normal in non-cholinergic forms of dementia, such as frontotemporal dementia. This finding suggests that this method can be used as a non-invasive additional tool for discriminating between cholinergic and non-cholinergic forms of dementia. Interestingly, SAI was also found to be significantly smaller in early AD patients. Identification of SAI abnormalities that occur early in the course of AD will allow earlier diagnosis and treatment with cholinergic drugs. In patients with vascular dementia, SAI responses varied widely; the number of patients with abnormal SAI conceivably reflects the percentage of subjects with a significant cholinergic dys-
\end{abstract}

function. It has recently been demonstrated that brain microbleeds have an impact on SAI that is independent of the extent of associated white matter changes and ischemic stroke. Since SAI can be increased by acetylcholinesterase inhibitors, TMS may help in identifying the patients who would be suitable for long-term treatment with cholinergic agents.

Copyright $\odot 2011$ S. Karger AG, Basel

\section{Short-Latency Afferent Inhibition}

Transcranial magnetic stimulation (TMS), a non-invasive method for the evaluation of excitatory/inhibitory characteristics of the motor cortex, allows direct investigation of motor cortex function [1]. By coupling peripheral nerve stimulation with TMS of the contralateral motor cortex, it is possible to recruit several neuronal circuits of the human brain $[2,3]$.

Afferent input can modify the excitability of the motor cortex with a complex time course [4]. Delwaide and Olivier [5] reported that median nerve stimulation at the wrist suppresses motor evoked potential (MEP) evoked by TMS 18-21 ms later in relaxed hand muscles. Similar effects could be seen after stimulation of the cutaneous

\section{KARGER \\ Fax +41613061234 \\ E-Mail karger@karger.ch}

www.karger.com

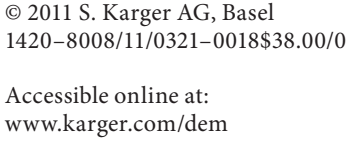

Dr. Raffaele Nardone

Department of Neurology, Franz Tappeiner Hospital

Via Rossini, 5

IT-39012 Merano (Italy)

Tel. +39 047326 4616, E-Mail raffaele.nardone@ asbmeran-o.it 
nerves of the index finger. This effect, named short-latency afferent inhibition (SAI), is produced by inhibitory interactions within the cerebral cortex $[2,3]$. SAI begins about $1 \mathrm{~ms}$ after latency of the N20 component of the somatosensory evoked potential obtained from median nerve stimulation and lasts for about 7-8 ms [2].

SAI is usually studied using the technique described by Tokimura et al. [2].

Conditioning stimuli are single pulses $(200 \mu \mathrm{s})$ of electrical stimulation (with the cathode positioned proximally) applied through bipolar electrodes to the median nerve at the wrist. The intensity of the conditioning stimuli is set at just over motor threshold for evoking a visible twitch of the thenar muscles. The intensity of the test cortical magnetic shock is adjusted to evoke a muscle response in relaxed first interosseous dorsal muscle with an amplitude of approximately $1 \mathrm{mV}$ peak to peak. The conditioning stimulus to the peripheral nerve precedes the test magnetic cortical stimulus. Interstimulus intervals (ISIs) are determined relative to the latency of the N20 component of the somatosensory evoked potential evoked by stimulation of the left median nerve. To record somatosensory evoked potentials, the active electrode for recording the $\mathrm{N} 20$ potential is attached $3 \mathrm{~cm}$ posterior to C4 (according to the 10-20 international EEG system), and the reference is $3 \mathrm{~cm}$ posterior to $\mathrm{C} 3$, respectively. Five hundred responses are averaged to identify the latency of the N20 peak. ISIs from the latency of the N20 component plus $2 \mathrm{~ms}$ to the latency of the $\mathrm{N} 20$ component plus $8 \mathrm{~ms}$ are investigated in steps of $1 \mathrm{~ms}$, because at these intervals there is a clear inhibition of the MEPs and of corticospinal volleys evoked by TMS.

Eight repeats are delivered for cortical magnetic stimulation alone and for conditioned stimulation at each ISI in pseudorandomized order. The amplitude of the conditioned MEP is expressed as a percentage of the amplitude of the test MEP. The percentage inhibition of the conditioned responses at the 7 different ISIs is averaged to obtain a grand mean of SAI. Subjects are given audiovisual feedback at high gain to assist in maintaining complete relaxation.

\section{Effects of Muscarinic Blockade on Cortical Excitability}

SAI has been shown in healthy subjects to be sensitive to the blockage of muscarinic acetylcholine (Ach) receptors [6]. The effects of the muscarinic receptor antagonist scopolamine on the excitability of human motor cortex have been investigated in 4 healthy subjects using TMS stimulation before and after an intravenous dose of scopolamine $(0.006 \mathrm{mg} / \mathrm{kg})$ [6]. The authors measured the following TMS parameters: the threshold for motor responses (which is thought to reflect primarily membrane excitability of the corticospinal motor neurons), the amplitude of motor responses, the duration of the cortical silent period (which is related to a long-lasting cortical inhibition mediated by $\gamma$-aminobutyric acid $\mathrm{B}, \mathrm{GABA}_{\mathrm{B}}$, receptors), the short-latency intracortical inhibition (SICI) and intracortical facilitation to paired TMS (which are believed to reflect the excitability of inhibitory GABAergic cortical circuits and to depend upon the activity of intracortical glutamatergic excitatory circuits, respectively) and SAI. In addition, the amplitude of motor responses evoked by electrical anodal stimulation was evaluated, since these responses originate from direct activation of corticospinal axons in the white matter and are not sensitive to changes in cortical excitability. Scopolamine decreased the threshold to magnetic stimuli and increased the amplitude of motor responses evoked by magnetic stimulation. In contrast, motor responses evoked by electrical stimulation were unaffected by administration of scopolamine. Scopolamine also led to a highly significant reduction in the amount of SAI; in contrast, SICI and intracortical facilitation were not modified by scopolamine. The differential effect of scopolamine on motor responses evoked by magnetic and electrical stimulation of the motor cortex and the selective effect on somatosensory inhibition demonstrate that muscarinic blockade modifies the excitability of specific cortical networks in the human motor cortex.

\section{Pharmacological Modulation of SAI}

SAI was found to be modulated by Ach in healthy subjects $[7,8]$. SAI is also influenced by GABAergic drugs such as some benzodiazepines in healthy subjects $[9,10]$ and by dopaminergic drugs in patients with Parkinson disease [11].

In particular, lorazepam, a benzodiazepine that leads to an impairment in memory function similar to that observed after scopolamine administration, results in a suppression of SAI [9]. This effect suggests that GABAergic circuits might also be involved in SAI. Pharmacological manipulations that produce amnesic effects also produce a deficit in SAI either when they impair cholinergic transmission like scopolamine or when they enhance 
transmission at the level of some GABAergic circuits like lorazepam $[6,9]$.

Recently, direct cholinergic inhibition of neocortical pyramidal neurons has been demonstrated in rats [12] and thus SAI might involve the circuits described in rat brains. This study also suggests that there are two different mechanisms through which cholinergic inputs modulate the pyramidal neurons; the first mechanism is indirect and acts through the modulation of inhibitory networks that are GABAergic in nature $[13,14]$; the second is the direct form of cholinergic neocortical pyramidal neurons [12].

Preliminary data suggest that other neurotransmitters/neuromodulators are likely not involved in the regulation of SAI in that quetiapine, an antagonist at multiple neurotransmitter receptors in the brain such as serotonin 5- $\mathrm{HT}_{1 \mathrm{~A}}$ and $5-\mathrm{HT}_{2}$, dopamine $\mathrm{D}_{1}$ and $\mathrm{D}_{2}$, histamine, and adrenergic $\alpha_{1^{-}}$and $\alpha_{2}$-receptors, does not modify SAI in healthy subjects [9]. Therefore, SAI is thought to represent a non-invasive way of testing the integrity of some cholinergic cortical circuits [15], while the contribution of neurotransmitters other than Ach is not well understood.

\section{SAl in Alzheimer Disease}

Post-mortem studies have shown that impaired central cholinergic neurotransmission has a central role in Alzheimer disease (AD) patients [16-19]. Di Lazzaro et al. [20] first evaluated SAI in 15 patients with AD and compared the data with those of 12 age-matched healthy controls. The authors found that SAI was significantly reduced in $\mathrm{AD}$; furthermore, a single dose of the acetylcholinesterase inhibitor rivastigmine significantly increased afferent inhibition in the 6 patients in whom it was tested. These findings supported the view that SAI may be a useful marker of cholinergic activity in some motor circuits of the cerebral cortex.

In a following study, it was evaluated whether SAI testing might be useful in predicting the response after 1 year of treatment with rivastigmine in $16 \mathrm{AD}$ patients [7]. SAI was increased after administration of a single oral dose of rivastigmine in $\mathrm{AD}$ patients with abnormal baseline SAI, but individual responses to rivastigmine varied widely, with SAI change ranging from an increase in inhibition of approximately $50 \%$ of test size to no change. Baseline SAI and the increase in SAI after a single dose of rivastigmine were correlated with response to long-term treatment. A normal SAI in baseline conditions, or an abnor- mal SAI in baseline conditions that was not greatly increased by a single oral dose of rivastigmine, were invariably associated with poor response to long-term treatment, while an abnormal SAI in baseline conditions in conjunction with a large increase in SAI after a single dose of rivastigmine was associated with good response to long-term treatment in most of the patients.

Interestingly, it has recently been reported that dopamine modifies SAI in AD [21]. Therefore, it should be considered that other neurotransmitters such as dopamine may be able to modulate cortical cholinergic function in $\mathrm{AD}$ patients.

Nardone et al. [22] evaluated SAI in a group of patients with early diagnosis of AD. The amount of SAI was significantly smaller in early AD patients than in controls. This study provided physiological evidence that a central cholinergic dysfunction occurs early in the course of dementia. These results support the concept that cholinergic impairment is an early and leading event in $\mathrm{AD}$.

Furthermore, SAI was found to be significantly reduced in adults with Down syndrome (DS) and Alzheimer-type dementia [23]; the values correlated with the patient's age and the score on the Dementia Scale for DS. SAI was increased after administration of a single dose of donezepil in a subgroup of 5 patients. This finding suggests that, with respect to this putative marker of central cholinergic activity, dementia in aging DS patients shares pathophysiological similarities to AD in the general population. This technique may help to clarify the pathophysiological basis of cognitive dysfunction in DS and may represent an additional tool for the diagnosis of Alzheimer-type dementia in subjects with DS.

\section{SAI in Dementia with Lewy Bodies and Frontotemporal Dementia}

Nardone et al. [24] first studied SAI in patients with Lewy body dementia (DLB) and showed a clear tendency toward a reduced SAI: mean responses were reduced to $56 \%$ of the test size in DLB patients and to about $46 \%$ of the test size in controls. These authors performed SAI testing without randomization of different conditions, and the diagnosis of DLB was based on criteria proposed in 1996 instead of the revised ones [25].

Di Lazzaro et al. [26] examined 10 patients with a clinical diagnosis of DLB according to the NINCDS-ADRDA criteria [25] and found a significantly reduced SAI in DLB patients. 
In agreement with this finding, neurochemical investigations have demonstrated the presence of cholinergic deficits in the brain of patients with DLB [27]. SAI explores sensorimotor interaction within the cerebral cortex [2]. Since in DLB patients an involvement of the parietal cortex was demonstrated by single-photon emission tomography, the abnormality of SAI could be related to the functional involvement of this area [28]. SAI investigation may also be useful in the distinction between DLB and Parkinson disease, because SAI is normal or even enhanced in Parkinson disease $[11,29]$.

SAI was evaluated in 20 patients with frontotemporal dementia, and the data were compared with those from 20 patients with $\mathrm{AD}$ and 20 control subjects [30]. SAI was normal in frontotemporal dementia, whereas it was reduced in AD. SAI may represent an additional tool to discriminate frontotemporal dementia from AD. These findings are consistent with post-mortem studies which show central cholinergic deficits in AD [16-19] but not in frontotemporal dementia [31].

\section{SAI in Vascular Dementia}

A reduced SAI was found in patients with vascular dementia (VD) but not to the same extent as in those with AD. Nardone et al. [32] reported that SAI responses in patients with subcortical ischemic VD (SVD) varied widely, ranging from normal to markedly reduced values. In another TMS study, significant SAI abnormalities were disclosed in 3 out of 12 patients with VD [33]. SAI was strongly correlated with neuropsychological measures of long-term memory and other cognitive functions.

The number of patients with abnormal SAI conceivably reflects the percentage of subjects with a significant cholinergic dysfunction among the patients with a clinical diagnosis of VD.

White matter lesions may directly affect cholinergic projection [34, 35], and preclinical $[36,37]$ and clinical $[38,39]$ evidence suggests that the cholinergic system may also be involved in VD.

In patients with cerebral autosomal dominant arteriopathy with subcortical infarcts and leukoencephalopathy (CADASIL), the amount of SAI was found to be significantly smaller than in normal subjects [40]. SAI was normal in the only patient that showed a normal neuropsychological evaluation. This finding supports the hypothesis of a central cholinergic system impairment in CADASIL. Interestingly, Mesulam et al. [41] demonstrat- ed that pure white matter infarcts, similar to those seen in SVD, can cause cortical cholinergic denervation, but in patterns that vary from those seen in $\mathrm{AD}$.

It should be considered that $\mathrm{AD}$ and $\mathrm{VD}$ are not mutually exclusive conditions and there is considerable overlap between these two forms of dementia as demonstrated by neuropathological studies that have shown the common coexistence of cerebrovascular and AD lesions [42-45]. VD patients with SAI abnormalities could have concomitant neuropathological changes of $\mathrm{AD}$ and thus represent the percentage of patients with a mixed form of dementia. Interestingly, neuropathological studies of VD have demonstrated that $25-30 \%$ of patients with the clinical diagnosis of VD show the concomitant neuropathology of AD $[19,46,47]$. This might be the case for at least one of the VD patients with abnormal SAI reported by $\mathrm{Di}$ Lazzaro et al. [33], who showed clinical findings suggestive of a mixed form of dementia at the extended follow-up.

There has been little investigation on the association between cognitive impairment and the microbleeds (MBs) frequently seen in SVD. In a recent study [48], this test was used in SVD patients with and without MBs; SAI was evaluated in 13 SVD patients with MBs, and the data were compared with those from a group of 15 SVD patients without MBs and with those from 20 healthy subjects. SAI was significantly reduced in the MB-positive group when compared with the MB-negative group and the control subjects. Adjustment for age, gender, education, presence of lacunae, severe white matter hyperintensities or severe periventricular hyperintensities did not affect these findings. This study provided physiological evidence that MBs have an impact on central cholinergic function that is independent of the extent of associated white matter changes and ischemic stroke.

\section{Discussion}

In animals, the cholinergic system has been implicated in a variety of activities including memory, learning and attention [49]. The pathogenesis of $\mathrm{AD}$ and other dementias appears to involve several different mechanisms, the most consistent of which is an impairment of cholinergic neurotransmission [50-52]. However, the role of the central cholinergic system in the different types of dementia needs to be further clarified also in view of implications for treatment with cholinergic agents.

SAI is thought to be related to central cholinergic activity because in normal subjects it can be reduced or 
abolished by intravenous injection of the muscarinic antagonist scopolamine and is positively modulated by Ach. Furthermore, drugs enhancing cholinergic transmission can increase SAI.

Changes in those cholinergic cortical networks that are involved in SAI have been demonstrated in about $70 \%$ of patients with a clinical diagnosis of AD. Abnormal SAI has also been reported in DLB [26], a form of dementia that responds to cholinergic medications [53]. In contrast, SAI was found to be normal in frontotemporal dementia [30], a non-cholinergic form of dementia. Therefore, SAI may be a marker of a dysfunction in some circuits related to memory function that are probably cholinergic in nature; SAI testing can be used as a noninvasive test for the assessment of cholinergic pathways in patients with dementia and may represent a useful additional tool in the differential diagnosis between the cholinergic forms and the non-cholinergic forms of dementia.

Moreover, the study of SAI seems to be useful in several other clinical conditions associated with a cognitive deficit.

Adults with DS also develop progressive cognitive impairment resembling the cognitive profile of AD [5456]. Although the specific neurobiological correlates of cognitive deficits in DS are still not completely understood, it has been proposed that cholinergic dysfunction may contribute to some of these deficits in DS who develop Alzheimer-type dementia. A reduced SAI was found in these patients [23]. These observations have demonstrated that the involvement of the central system in $\mathrm{DS}$ individuals may be similar to that of $\mathrm{AD}$ in the general population and that this cholinergic deficiency might be responsible for the intellectual changes seen in this disease.

There are a few in vivo studies that indicate a significant impairment of the cholinergic system at the early stage of $\mathrm{AD}$, and most of them are subject to methodological limitations such as very small subject numbers. In any case, both in vivo and post-mortem studies on cholinergic involvement in AD are inconclusive [57-60]. Consequently, it remains relatively unclear how early in the course of the disease neurochemical and neuropathological alterations occur. However, neurobiological changes should be examined earlier in the disease process, when presumably they are more relevant for the pathogenesis of $\mathrm{AD}$. Therefore, the finding that SAI abnormalities can be observed also in patients with early diagnosis of $\mathrm{AD}[22]$ has potential diagnostic and therapeutic implications. Indeed, identification of SAI abnor- malities that occur early in the course of AD will allow earlier diagnosis and treatment with cholinergic drugs.

By contrast, SAI was found to be not significantly reduced in 16 subjects with amnestic mild cognitive impairment, compared with normal controls [61]. However, it should be noted that the diagnosis of amnestic mild cognitive impairment was based on criteria proposed by Petersen in 1999 instead of the revised ones [62] and the relationships to the different mild cognitive impairment subtypes was not defined.

AD patients show a slight and variable reduction in SICI [20, 63-65]. Reduced SICI suggests a dysregulation of the intracortical GABAergic inhibitory circuitries; the reduction of GABA activity in $\mathrm{AD}$ patients could be interpreted as a compensatory mechanism to enhance cholinergic transmission. In fact, GABA affects cholinergic neurotransmission at multiple central nervous system levels [66]. $\mathrm{GABA}_{\mathrm{A}}$ antagonists enhance the release of Ach at the level of the cerebral cortex in rats $[66,67]$ and at the forebrain level in cats [68]. Vice versa, cortical interneurons containing GABA have nicotinic as well as muscarinic receptors and receive rich cholinergic afferents [69]. The muscarinic receptors are involved in the control of inhibition on the layer $\mathrm{V}$ pyramidal neurons [69]; moreover, the GABAergic inhibition to the layer $\mathrm{V}$ pyramidal neurons is enhanced via the activation of $\alpha_{4} \beta_{2}$-nicotinic receptors [70]. It could be that the altered nicotinic receptor function described in $\mathrm{AD}$ [71] may deprive the GABAergic inhibitory neurons of a source of excitatory inputs.

The second most frequent cause of dementia following $\mathrm{AD}$ is VD. Little is known about the neurochemical pathology of VD; it was suggested that cholinergic mechanisms play a role also in the pathogenesis of VD. However, the role of the cholinergic system in the development of cognitive impairment is still under discussion in VD, also because there are conflicting results on the role of the central cholinergic activity evaluated by SAI. Di Lazzaro et al. [33] found in most VD patients that there is no alteration of the central cholinergic circuits. On the other hand, Manganelli et al. [40] and Nardone et al. [32] suggest that the cholinergic neurotransmission can play an important role in the cognitive decline of CADASIL and SVD patients, respectively. A possibility is that the subcortical lesions in VD interrupt ascending cholinergic axons determining cortical cholinergic denervation as suggested by Mesulam et al. [41] for CADASIL patients.

Whether the evaluation of the non-invasive test SAI might be useful for evaluating the pharmacological effects of cholinergic drugs or even predicting the clinical 
response to treatment in VD patients, similar to that previously reported in $\mathrm{AD}$ patients $[7,20]$, remains to be proven in carefully designed future trials.

It should be noted that SAI studies in patients with VD have some limitations. There is, without post-mortem histology, no way of currently confirming the precise nature of dementia. Another limitation of the studies is that a simple visual evaluation of magnetic resonance imaging (MRI) was employed and not more advanced neuroimaging techniques that could contribute to the identification of different forms of dementia. It would be extremely interesting to correlate SAI levels with any abnormality in the medial temporal lobe, including the amygdala, anterior hippocampus and entorhinal cortex by using quantitative MRI measures, such as voxel-based morphometry [72] and to evaluate whether these techniques may reveal abnormalities in VD patients with reduced SAI.

Anyway, VD is a highly heterogeneous condition and the possibility of different patterns of cholinergic deficits should be considered. VD patients have vascular lesions that are affecting cholinergic pathways in different ways. In contrast to $\mathrm{AD}$ where the major features of the cholinergic neuropathology show few interindividual variations, VD may show considerable interindividual variation in the location of subcortical infarcts and, therefore, in the distribution and magnitude of the resultant cortical cholinergic denervation. A recent study [48] indicated that the cumulative effect of MBs on cognition appears to be independent of coexisting ischemic cerebrovascular disease, and in particular is independent of the severity of ischemic SVD as assessed by MRI white matter changes. The presence of MBs may thus imply a much severer disruption of the neural network between cortical and subcortical structures than ischemic SVDs. MBs would be expected to cause cognitive impairment if they disrupt strategically important white matter tracts or eloquent cortical areas. Since MBs are particularly common in the white matter regions [73], it could be hypothesized that executive functions would be most affected, due to disruption of frontal-basal ganglia connections. The finding that MBs are associated with cholinergic dysfunction has potential diagnostic and therapeutic implications. It would be of particular interest to explore in future studies the responsiveness of patients with MBs, stratified according to their cholinergic dysfunction, defined using SAI, to acetylcholinesterase inhibitors. TMS studies may be important for evaluating the causes of cognitive impairment in cerebrovascular disease. Thus, in patients with cerebrovascular risk factors and cognitive impairment, $\mathrm{T}_{2}{ }^{*}$-weighted gadolinium-enhanced MRI may be a helpful adjunct to standard MRI in clarifying the mechanism of cognitive impairment.

In conclusion, many neurophysiological studies showed that SAI testing may represent a useful additional tool for the functional evaluation of patients with dementia.

\section{References}

1 Hallett M: Transcranial magnetic stimulation and the human brain. Nature 2000;406: 147-150.

$\checkmark 2$ Tokimura H, Di Lazzaro V, Tokimura Y, Oliviero A, Profice P, Insola A, Mazzone P, Tonali P, Rothwell JC: Short latency inhibition of human hand motor cortex by somatosensory input from the hand. J Physiol 2000;523: 503-513.

3 Di Lazzaro V, Oliviero A, Pilato F, Saturno E, Dileone M, Mazzone P, Insola A, Tonali PA, Rothwell JC: The physiological basis of transcranial motor cortex stimulation in conscious humans. Clin Neurophysiol 2004; 115:255-266

4 Mariorenzi R, Zarola F, Caramia MD, Paradiso C, Rossini PM: Non-invasive evaluation of central motor tract excitability changes following peripheral nerve stimulation in healthy humans. Electroencephalogr Clin Neurophysiol 1991;81:90-101.
5 Delwaide PJ, Olivier E: Conditioning transcranial cortical stimulation (TCCS) by exteroceptive stimulation in parkinsonian patients. Adv Neurol 1990;53:175-181.

-6 Di Lazzaro V, Oliviero A, Profice P, Pennisi MA, Di Giovanni S, Zito G, Tonali P, Rothwell JC: Muscarinic receptor blockade has differential effects on the excitability of intracortical circuits in the human motor cortex. Exp Brain Res 2000;135:455-461.

7 Di Lazzaro V, Oliviero A, Pilato F, Saturno E, Dileone M, Marra C, Ghirlanda S, Ranieri F, Gainotti G, Tonali PA: Neurophysiological predictors of long term response to AChE inhibitors in AD patients. J Neurol Neurosurg Psychiatry 2005;76:1064-1069.

-8 Fujiki M, Hikawa T, Abe T, Ishii K, Kobayashi H: Reduced short latency afferent inhibition in diffuse axonal injury patients with memory impairment. Neurosci Lett 2006; 405:226-230.
-9 Di Lazzaro V, Oliviero A, Saturno E, Dileone M, Pilato F, Nardone R, Ranieri F, Musumeci G, Fiorilla T, Tonali P: Effects of lorazepam on short latency afferent inhibition and short latency intracortical inhibition in humans. J Physiol 2005;564:661-668.

10 Di Lazzaro V, Pilato F, Dileone M, Tonali PA, Ziemann U: Dissociated effects of diazepam and lorazepam on short-latency afferent inhibition. J Physiol 2005;569:315-323.

11 Sailer A, Molnar GF, Paradiso G, Gunraj CA, Lang AE, Chen R: Short and long latency afferent inhibition in Parkinson's disease. Brain 2003;26:1883-1894.

12 Guillegde AT, Stuart GJ: Cholinergic inhibition of neocortical pyramidal neurons. J Neurosci 2005;25:10308-10320.

13 McCormick DA, Prince DA: Mechanisms of action of acetylcholine in the guinea-pig-cerebral cortex in vitro. J Physiol 1986;375:169194. 
14 Müller CM, Singer W: Acetylcholine-induced inhibition in the cat visual cortex is mediated by a GABAergic mechanism. Brain Res 1989;487:335-342.

15 Ziemann U: TMS and drugs. Clin Neurophysiol 2004;115:1717-1729.

16 Davies P, Maloney AJ: Selective loss of central cholinergic neurons in Alzheimer's disease. Lancet 1976;2:1403.

-17 Whitehouse PJ, Price DL, Struble RG, Clark AW, Coyle JT, Delon MR: Alzheimer's disease and senile dementia: loss of neurons in the basal forebrain. Science 1982;215:12371239.

-18 Coyle JT, Price DL, DeLong MR: Alzheimer's disease: a disorder of cortical cholinergic innervation. Science 1983;219:1184-1190.

19 Geula C, Mesulam MM: Cholinergic systems in Alzheimer's disease; in Terry RD, Katzman R, Bick KL, Sisodia SS (eds): Alzheimer Disease, ed 2. Philadelphia, Lippincott, Williams \& Wilkins, 1999.

-20 Di Lazzaro V, Oliviero A, Tonali PA, Marra C, Daniele A, Profice P, Saturno E, Pilato F, Masullo C, Rothwell JC: Noninvasive in vivo assessment of cholinergic cortical circuits in $\mathrm{AD}$ using transcranial magnetic stimulation. Neurology 2002;59:392-397.

-21 Martorana A, Mori F, Esposito Z, Kusayanagi $\mathrm{H}$, Monteleone $\mathrm{F}$, Codecà $\mathrm{C}$, Sancesario G, Bernardi G, Koch G: Dopamine modulates cholinergic cortical excitability in Alzheimer's disease patients. Neuropsychopharmacology 2009;34:2323-2328.

-22 Nardone R, Bergmann J, Kronbichler M, Kunz A, Klein S, Caleri F, Tezzon F, Ladurner G, Golaszewski S: Abnormal short latency afferent inhibition in early Alzheimer's disease: a transcranial magnetic demonstration. J Neural Transm 2008;115:1557-1562.

-23 Nardone R, Marth R, Ausserer H, Bratti A, Tezzon F: Reduced short latency afferent inhibition in patients with Down syndrome and Alzheimer-type dementia. Clin Neurophysiol 2006;117:2204-2210.

-24 Nardone R, Bratti A, Tezzon F: Motor cortex inhibitory circuits in dementia with Lewy bodies and in Alzheimer's disease. J Neural Transm 2006;113:1679-1684.

25 McKeith IG, Dickson DW, Lowe J, Emre M, O'Brien JT, Feldman H, et al: Consortium on DLB. Diagnosis and management of dementia with Lewy bodies: third report of the DLB Consortium. Neurology 2005;65:863-872.

-26 Di Lazzaro V, Pilato F, Dileone M, Saturno E, Profice P, Marra C, Daniele A, Ranieri F, Quaranta D, Gainotti G, Tonali PA: Functional evaluation of cerebral cortex in dementia with Lewy bodies. Neuroimage 2007; 37:422-429.

-27 Tiraboschi P, Hansen LA, Alford M, Sabbagh MN, Schoos B, Masliah E, Thal LJ, CoreyBloom J: Cholinergic dysfunction in diseases with Lewy bodies. Neurology 2000;54:407411.
28 Colloby SJ, Fenwick JD, Williams ED, Paling SM, Lobotesis K, Ballard C, McKeith I, O'Brien JT: A comparison of ${ }^{99 \mathrm{~m}} \mathrm{Tc}-\mathrm{HMPAO}$ SPET changes in dementia with Lewy bodies and Alzheimer's disease using statistical parametric mapping. Eur J Nucl Med Mol Imaging 2002;29:615-622.

29 Di Lazzaro V, Oliviero A, Pilato F, Saturno E, Dileone M, Bentivoglio AR, Tonali PA: Normal or enhanced short-latency afferent inhibition in Parkinson's disesase? Brain 2004; 127:E8.

30 Di Lazzaro V, Pilato F, Dileone M, Saturno E, Oliviero A, Marra C, Daniele A, Ranieri F Gainotti G, Tonali PA: In vivo cholinergic circuit evaluation in frontotemporal and Alzheimer dementias. Neurology 2006;66: 1111-1113.

31 Procter AW, Qurne M, Francis PT: Neurochemical features of frontotemporal dementia. Dement Geriatr Cogn Disord 1999; 10(suppl 1):80-84

32 Nardone R, Bergmann J, Tezzon F, Ladurner G, Golaszewski S: Cholinergic dysfunction in subcortical ischaemic vascular dementia: a transcranial magnetic stimulation study. J Neural Transm 2008;115:737-743.

-33 Di Lazzaro V, Pilato F, Dileone M, Profice P, Marra C, Ranieri F, Quaranta D, Gainotti G, Tonali PA: In vivo functional evaluation of central cholinergic circuits in vascular dementia. Clin Neurophysiol 2008;119:24942500.

-34 Selden NR, Gitelman DR, Salamon-Murayama N, Parrish TB, Mesulam MM: Trajectories of cholinergic pathways within the cerebral hemispheres of the human brain. Brain 1998;121:2249-2257.

-35 Swartz RH, Sahlas DJ, Black SE: Strategic involvement of cholinergic pathways and executive dysfunction: does location of white matter signal hyperintensities matter? J Stroke Cerebrovasc Dis 2003;12:29-36.

-36 Togashi H, Matsumoto M, Yoshioka M, Hirokami M, Minami M, Saito H: Neurochemical profiles in cerebrospinal fluid of strokeprone spontaneously hypertensive rats. Neurosci Lett 1994;166:117-120.

\$37 Kimura S, Saito H, Minami M, Togashi H, Nakamura N, Nemoto M, Parvez HS: Pathogenesis of vascular dementia in stroke-prone spontaneously hypertensive rats. Toxicology 2000;153:167-178.

-38 Gottfries CG, Blennow K, Karlsson I, Wallin A: The neurochemistry of vascular dementia. Dementia 1994;5:163-167.

39 Martin-Ruiz C, Court J, Lee M, Piggott M, Johnson M, Ballard C, Kalaria R, Perry R, Perry E: Nicotinic receptors in dementia of Alzheimer, Lewy body and vascular types. Acta Neurol Scand Suppl 2000;176:34-41.

40 Manganelli F, Ragno M, Cacchio G, Iodice V, Trojano L, Silvaggio F, Scarcella M, Grazioli M, Santoro L, Perretti A: Motor cortex cholinergic dysfunction in CADASIL: a transcranial magnetic demonstration. Clin Neurophysiol 2008;119:351-355.
41 Mesulam M, Siddique T, Cohen B: Cholinergic denervation in pure multi-infarct state: observations in CADASIL. Neurology 2003; 60:1183-1185.

42 Esiri MM, Wilcock GK, Morris JH: Neuropathological assessment of the lesions of significance in vascular dementia. J Neurol Neurosurg Psychiatry 1997;63:749-753.

$\checkmark 43$ Heyman A, Fillenbaum GG, Welsh-Bohmer KA, Gearing M, Mirra SS, Mohs RC, Peterson BL, Pieper CF: Cerebral infarcts in patients with autopsy-proven Alzheimer's disease, CERAD part XVIII. Neurology 1998; 51:159-162.

44 Nagy Z, Esiri MM, Joachim C, Jobst KA, Morris JH, King EM, Hindley NJ, McDonald B, Litchfield S, Barnetson L, Smith AD, et al: Comparison of pathological diagnostic criteria for Alzheimer disease. Alzheimer Dis Assoc Disord 1998;12:182-189.

-45 Premkumar DRD, Cohen DL, Hedera P, Friedland RP, Kalaria RN: Apolipoprotein 4 alleles in cerebral amyloid angiopathy and cerebrovascular pathology in Alzheimer's disease. Am J Pathol 1996;148:2083-2095.

46 Vinters HV, Ellis WG, Zarow C, Zaias BW, Jagust WJ, Mack WJ, Chui HC: Neuropathological substrates of ischemic vascular dementia. J Neuropathol Exp Neurol 2000;59: 931-945.

47 Kalaria RN, Ballard K: Overlap between pathology of Alzheimer disease and vascular dementia. Alzheimer Dis Relat Disord 1999; 13:S115-S123.

48 Nardone R, De Blasi P, Seidl M, Höller Y, Caleri F, Tezzon F, Ladurner G, Golaszewski S, Trinka E: Cognitive function and cholinergic transmission in patients with subcortical vascular dementia and microbleeds: a TMS study. J Neural Transm 2011, Epub ahead of print.

49 Smith G: Animal models of Alzheimer's disease: experimental cholinergic denervation. Brain Res Rev 1988;13:103-118.

50 Kasa P, Rakonczay Z, Gulya K: The cholinergic system in Alzheimer's disease. Prog Neurobiol 1997;52:511-535.

-51 Bartus RT, Emerich DF: Cholinergic markers in Alzheimer disease. J Am Med Assoc 1999; 282:2208-2209.

52 Mufson EJ, Ma SY, Cochran EJ, Bennett DA, Beckett LA, Jaffar S, Saragovi HU, Kordower $\mathrm{JH}$ : Loss of nucleus basalis neurons containing trkA immunoreactivity in individuals with mild cognitive impairment and early Alzheimer's disease. J Comp Neurol 2000; 427:9-30.

$\checkmark 53$ Emre M, Aarsland D, Albanese A, Byrne EJ, Deuschl G, De Deyn PP, Durif F, Kulisevsky J, van Laar T, Lees A, Poewe W, Robillard A, Rosa MM, Wolters E, Quarg P, Tekin S, Lane $\mathrm{R}$ : Rivastigmine for dementia associated with Parkinson's disease. N Engl J Med 2004; 351:2509-2518.

54 Lai F, Williams RS: A prospective study of Alzheimer disease in Down syndrome. Arch Neurol 1989;46:849-853. 
55 Evenhuis HM: The natural history of dementia in Down's syndrome. Arch Neurol 1990;47:263-267.

56 Shapiro B, Haxby JV, Grady CL: Nature of mental retardation and dementia in Down syndrome: study with PET, CT, and neuropsychology. Neurobiol Aging 1992;13:723734.

57 Rinne JO, Kaasinen V, Jarvenpaa T, Nagren K, Roivainen A, Yu M, Oikonen V, Kurki T: Brain acetylcholinesterase activity in mild cognitive impairment and early Alzheimer's disease. J Neurol Neurosurg Psychiatry 2003;74:113-115.

58 Herholz K, Weisenbach S, Zundorf G, Lenz O, Schroder H, Bauer B, Kalbe E, Heiss WD: In-vivo study of acetylcholine esterase in basal forebrain, amygdala, and cortex in mild to moderate Alzheimer disease. Neuroimage 2004;21:136-143.

-59 Stokin GB, Lillo C, Falzone TL, Brusch RG, Rockenstein E, Mount SL, Raman R, Davies P, Masliah E, Williams DS, Goldstein LS: Axonopathy and transport deficits early in the pathogenesis of Alzheimer's disease. Science 2005;307:1282-1288.

60 O’Brien JT, Colloby SJ, Pakrasi S, Perry EK, Pimlott S, Land DJ, Wyper DJ, McKeith IG, Williams ED: Alpha4beta2 nicotinic receptor status in Alzheimer's disease using 123I5IA-85380 single-photon-emission computed tomography. J Neurol Neurosurg Psychiatry 2007;78:356-362.
61 Sakuma K, Murakami T, Nakashima K: Short latency afferent inhibition is not impaired in mild cognitive impairment. Clin Neurophysiol 2007;118:1460-1463.

62 Petersen RC, Doody R, Kurz A, Mohs RC, Morris JC, Rabins PV, Ritchie K, Rossor M, Thal L, Winblad B: Current concepts in mild cognitive impairment. Arch Neurol 2001;58: 1985-1992.

63 Liepert J, Bar KJ, Meske U, Weiller C: Motor cortex disinhibition in Alzheimer's disease. Clin Neurophysiol 2001;112:1436-1441.

64 Pierantozzi M, Panella M, Palmieri MG, Koch G, Giordano A, Marciani MG, Bernardi, Stanzione P, Stefani A: Different TMS patterns of intracortical inhibition in early onset Alzheimer dementia and frontotemporal dementia. Clin Neurophysiol 2004; 15: 2410-2418.

65 Pepin JL, Bogacz D, de Pasqua V, Delwaide PJ: Motor cortex inhibition is not impaired in patients with Alzheimer's disease: evidence from paired transcranial magnetic stimulation. J Neurol Sci 1999;170:119-123.

66 Giorgetti M, Bacciottini L, Giovannini MG, Colivicchi MA, Goldfarb J, Blandina P: Local GABAergic modulation of acetylcholine release from the cortex of freely moving rats. Eur J Neurosci 2000;12:1941-1948.

67 Diez-Ariza M, Garcia-Alloza M, Lasheras B, Del Rio J, Ramirez MJ: $\mathrm{GABA}_{\mathrm{A}}$ receptor antagonists enhance cortical acetylcholine release induced by $5-\mathrm{HT}_{3}$ receptor blockade in freely moving rats. Brain Res 2002;956:8185.
68 Vasquez J, Baghdoyan HA: Muscarinic and $\mathrm{GABA}_{\mathrm{A}}$ receptors modulate acetylcholine release in feline basal forebrain. Eur J Neurosci 2002;17:249-259.

69 Xiang Z, Huguenard JR, Prince DA: Cholinergic switching within neocortical inhibitory networks. Science 1998;281:985-988.

70 Alkondon M, Albuquerque EX: The nicotinic acetylcholine receptor subtypes and their function in the hippocampus and cerebral cortex. Prog Brain Res 2004;145:109-120.

71 Giacobini E, De Sarno P, Clark B, McIlhany M: The cholinergic receptor system of the human brain: neurochemical and pharmacological aspects in aging and Alzheimer. Prog Brain Res 1989;79:335-343.

72 Whitwell JL, Przybelski SA, Weigand SD, Knopman DS, Boeve BF, Petersen RC, Jack CR: 3D maps from multiple MRI illustrate changing atrophy patterns as subjects progress from mild cognitive impairment to Alzheimer's disease. Brain 2007;130:17771786.

73 Offenbacher H, Fazekas F, Schmidt R, Koch M, Fazekas G, Kapeller P: MR of cerebral abnormalities concomitant with primary intracerebral hematomas. AJNR Am J Neuroradiol 1996;17:573-578. 